\title{
El arancel integrado comunitario. Un caso práctico.
}

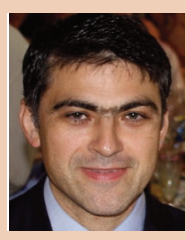

Juan Alberto Sanchis Llopis

Profesor Titular del Departament d'Estructura Econòmica de la Facultat d'Economia de la Universitat de València Juan.A.Sanchis@uv.es

|Fecha presentación: 07/10/2009 | Aceptación: 01/02/2010 |Publicación: 04/06/2010

\section{Resumen}

El arancel es el instrumento de política comercial más importante para proteger la producción doméstica de un país frente a la competencia exterior. La aplicación práctica del arancel es compleja puesto que implica conocer conceptos tales como el valor en aduana, el origen de las mercancías, etc. Este artículo presenta en un caso práctico cómo aplicar los aranceles en la importación de un producto, poniendo a disposición del alumno los recursos necesarios para calcular los aranceles. Este cálculo permitirá seleccionar al proveedor más competitivo entre los propuestos. Este caso ilustra cómo los aranceles determinan la competitividad internacional de un país.

Palabras clave: arancel; valor en aduana; origen de las mercancías; competitividad.

\section{Resum}

L'aranzel es l'instrument de política comercial més important per protegir la producció domèstica d'un país front a la competència exterior. La aplicació pràctica de l'aranzel es complexa donat que implica conèixer conceptes com el valor a la duana, l'origen de les mercaderies, etc. Aquest article presenta en un cas pràctic com aplicar els aranzels en la importació d'un producte, posant a disposició de l'alumne els recursos necessaris per a calcular els aranzels. Aquest càlcul permetrà seleccionar al proveïdor més competitiu entre els proposats. Aquest cas ill.lustra cóm els aranzels determinen la competitivitat internacional d'un país.

Paraules clau: aranzel; valor en duana; origen de les mercaderies; competitivitat.

\begin{abstract}
Tariffs are the most important trade policy instrument to protect domestic production from foreign competition. The application of tariffs is complex as it implies to know concepts like the customs value, the origin of the imports, etc. This article presents a practical case on how to implement the tariff for the import of a specific good, providing the necessary tools to calculate the tariff for an import. This estimation would allow selecting the most competitive provider among the proposed in the case. This case illustrates how tariffs determine the international competitiveness of a country.
\end{abstract}

Keywords: tariff, customs value, merchandises origin; competitiveness. 


\section{Introducción}

Los aranceles constituyen uno de los instrumentos de política comercial más importantes para proteger la producción nacional. Prácticamente todos los países imponen aranceles para proteger su producción doméstica de la competencia internacional. También hay que señalar que los aranceles pueden utilizarse para discriminar a algunos países frente a otros como proveedores. Desde el punto de vista teórico los aranceles no son más que un impuesto a la importación. Sin embargo, su aplicación práctica supone tener en cuenta una serie de aspectos (el valor en aduana, el origen de las mercancías,...) para la correcta aplicación de dichos impuestos cuando una empresa importa mercancías de terceros países.

El objetivo de este artículo es ilustrar de forma práctica, mediante un caso de estudio, cómo se calculan los aranceles a la importación, lo que permitirá analizar cómo los aranceles, a través de la distorsión en los precios de las importaciones permiten proteger a los productores nacionales de la competencia internacional. Esta práctica forma parte del tema Instrumentos de política comercial de un curso de Economía Internacional. En la parte de teoría correspondiente a este tema se explican cuestiones relacionadas con el arancel como instrumento de política comercial. Sin embargo, es difícil para los alumnos entender cómo los aranceles pueden proteger a la producción nacional de la competencia internacional o cómo los aranceles pueden discriminar a unos países frente a otros como proveedores.

Para explicar cómo se aplican los aranceles es necesario explicar los tres conceptos básicos del arancel integrado comunitario (que es el arancel que aplican los países que forman parte de la Unión Europea como España): el arancel de adunas (nomenclatura y tarifas arancelarias), el valor en aduana (que constituye la base imponible sobre la que se calculan los aranceles) y el origen de las mercancías (puesto que las tarifas arancelarias pueden ser distintas en función del país origen de una mercancía).

Para resolver esta práctica los alumnos reciben información en la que se les explica cómo acceder a una página web en la que pueden buscar toda la información necesaria para poder calcular los aranceles del producto objeto de importación. La información recogida por los alumnos será utilizada en la clase de prácticas para contestar a una serie de preguntas relacionadas con la importación de un determinado producto y con el cálculo de aranceles.

El objetivo de la práctica es que el alumno sea capaz de calcular los aranceles en función del país importador y poder comparar las ofertas propuestas con la información completa de los aranceles. El cálculo de los aranceles les permitirá a los alumnos entender cómo los aranceles constituyen una protección de la producción nacional frente al exterior a través del aumento de los precios de los productos que vienen del exterior y cómo los aranceles pueden discriminar a los productores de unos países frente a otros como proveedores.

$\mathrm{El}$ resto de este artículo se organiza de la siguiente manera. En la segunda sección se presentan los conceptos teóricos necesarios para calcular los aranceles a la importación. En la tercera sección se presenta el anuncio de un caso práctico y su resolución. Finalmente, en la cuarta sección se presentan unas breves conclusiones.

\section{El arancel integrado comunitario y otros conceptos básicos}

El arancel integrado comunitario (TARIC) es un instrumento económico-fiscal clave en la Unión Aduanera de la Unión Europea (U.E.) ya que es el elemento principal de protección comercial frente al exterior. Este impuesto se recauda en las aduanas. Las aduanas son oficinas públicas que los estados sitúan junto a sus fronteras, puertos, aeropuertos, etc., con una doble misión: por una parte controlan y fiscalizan el tránsito de viajeros y mercancías que accedan o abandonen el territorio, por otra parte, las aduanas se encargan de percibir los gravámenes a la importación (o exportación) de mercancías según el país de origen al que pertenezcan dichos bienes.

El arancel de aduanas comunitario está compuesto por la nomenclatura arancelaria, que determina la estructura y ordenación de las mercancías; y, la tarifa arancelaria, que es el gravamen que se aplica a cada producto para establecer el nivel de protección. Además, en la Unión Europea actualmente el Arancel Integrado Comunitario incluye un conjunto de medidas de política comercial y arancelaria y la Política Agrícola Común. Éstas son una serie de medidas no arancelarias establecidas en el marco de la Política Comercial Común aplicables a la exportación e importación, como son las medidas de vigilancia o salvaguardia, las restricciones o límites cuantitativos y las prohibiciones.

A continuación se explica con más detalle el sistema de nomenclatura del arancel integrado comunitario (TARIC). La Comunidad Económica Europea (CEE), en 1987, adoptó como estructura o denominación de las mercancías el Sistema Armonizado para la Designación y Clasificación de las Mercancías (SA) surgido de un convenio firmado por los principales comerciantes mundiales. Sin embargo, al adoptarlo lo denominó Nomenclatura Combinada (NC) ya que incorpora además del SA otras sub-partidas y disposiciones, así como las reglas generales interpretativas del SA para clasificar las mercancías ${ }^{1}$. El TARIC incluye además las subpartidas TARIC necesarias para la designación de las mercancías que sean objeto de medidas específicas (como por ejemplo el comercio entre estados miembros). Es importante utilizar la nomenclatura correcta para una mercancía porque necesitamos incluir la nomenclatura de cada mercancía en los documentos de comercio (documentos de exportación y/o importación) y, además, nos permite saber cuánto hay que pagar por un producto importado en concepto de aranceles.

Las tarifas arancelarias son los gravámenes que deben satisfacerse para introducir una mercancía en un territorio aduanero distinto al de su origen. Su finalidad básica es la de proteger la actividad económica del país frente a la competencia de los productos extranjeros importados. Pretenden ante todo encarecer el costo de las mercancías importadas de países terceros (que no pertenecen a la U.E.). Los aranceles también permiten discriminar entre unos países frente a otros como proveedores puesto que en función del origen de la mercancía podemos encontrar aranceles distintos para los mismos productos ${ }^{2}$.

\footnotetext{
${ }^{1}$ Reglamento CEE 2658/1987. Véase Operativa y práctica del comercio exterior, (2005) para una descripción más detallada del arancel integrado comunitario.

2 Por ejemplo, las importaciones de avellanas a España procedentes de Chile tienen un arancel inferior al arancel que se impone a la importación avellanas, de las mismas características, producidas en EE.UU.
} 
Existen 4 tipos básicos de derechos arancelarios: los derechos ad-valorem, que son aquellos en los que la cuota impositiva es un porcentaje del valor en aduana de la mercancía; los derechos específicos, que son los que se expresan en unidades monetarias a percibir por cada unidad física de producto (peso, volumen, superficie); los derechos mixtos, que son aquellos que están integrados por un derecho ad-valorem más un derecho específico; y, los derechos compuestos, que son un derecho ad-valorem con un límite inferior y/o superior determinado mediante derechos específicos ${ }^{3}$.

Una vez hemos visto que la cuota impositiva es un porcentaje del valor en aduana de las mercancías necesitamos saber cómo se calcula dicho valor en aduana.

El valor en aduana es el precio (en euros) que se estima que pudiera fijarse para las mercancías, en el momento en que los derechos de aduana son exigibles, como consecuencia de una venta efectuada en condiciones de libre competencia ${ }^{4}$. Existe un método principal para determinar el valor en aduana ${ }^{5}$, que es el valor de transacción de las mercancías, definido como el precio pagado o por pagar cuando estas se venden para la exportación con destino al país importador, siempre y cuando se cumplan dos requisitos: no existan restricciones para la utilización por parte del comprador; y, no exista vinculación entre comprador y vendedor.

El valor de transacción es el precio de la factura más una serie de gastos (gastos de transporte, envases y embalajes) ${ }^{6}$ y menos una serie de gastos (gastos de transporte desde la entrada en el territorio aduanero comunitario, la comisión de compra, los derechos de importación) ${ }^{7}$. Por tanto, el valor en aduana no comprende los gastos de transporte y seguros posteriores a la importación.

En aquellas ocasiones en las que no se puede utilizar el método principal para determinar el valor en aduana, la alternativa es utilizar los métodos subsidiarios. Estos métodos son, por orden de aplicación: el valor de transacción de mercancías idénticas, el valor de transacción de mercancías similares, el procedimiento sustractivo, el valor reconstruido (coste de producción), y, como último recurso la combinación de los anteriores.

El soporte documental necesario para fijar el valor en aduana está constituido por dos documentos: la factura comercial y el formulario DV-l.

El segundo concepto importante para poder aplicar las tarifas arancelarias es el origen de las mercancías. Esto es así porque los derechos arancelarios serán distintos para una mercancía idéntica en función del origen de dicha mercancía. En función del origen de la mercancía los aranceles permiten discriminar a unos países frente a otros como proveedores.

El origen de una mercancía es el vínculo geográfico de dicha mercancía con un país determinado del que se considera ha surgido. En la U.E. no existe aplicación de normas de origen más que para los intercambios con terceros países, ya que existe libre circulación en el interior, y además, una vez el producto originario de un tercer país ha sido importado y se encuentra a libre práctica, adquiere carácter comunitario 8 y a partir de ese momento no se le puede exigir su origen.

En las mercancías en cuya producción han intervenido dos o más países, su origen será el país donde se haya efectuado la última transformación o elaboración sustancial, económicamente justificada, y que haya conducido a la obtención de un producto nuevo o que represente un grado de transformación importante.

Para justificar el origen de las mercancías existen distintos sistemas, en función de si son mercancías que van a ser exportadas o mercancías que van a ser importadas. Así, para justificar el origen comunitario de las mercancías a la exportación se solicita el certificado de origen comunitario en Aduanas o Cámaras de Comercio dentro de la U.E. Para justificar el origen de las mercancías a la importación distinguimos dos regímenes. Por una parte el régimen normal, según el cual las mercancías deberán ir acompañadas, para declarar su origen, de un certificado de origen no normalizado (expedido por cónsules, agregados comerciales, cámaras, etc. en países de fuera de la U.E.). Asimismo, en el marco de los acuerdos con países con los que existen intensos intercambios en los dos sentidos, existe una justificación especial del origen que consiste en una declaración del exportador en la factura o en un documento unido a la declaración de importación (su texto se determina reglamentariamente). Por otra parte, existe el régimen preferencial. Para que una mercancía se pueda beneficiar de un tratamiento arancelario preferencial a su importación en la U.E. es necesario que dicha mercancía vaya acompañada del certificado de origen que justifique el carácter originario de la misma. Estos certificados pueden ser de tres tipos: el certificado EUR1 para países con los que la U.E. tiene acuerdos comerciales; el certificado Form A para países del Sistema de Preferencias Generalizadas 9 ; y el certificado ATR para las importaciones de Turquía.

\section{Caso práctico: Cálculo de los aranceles a la impor- tación de avellanas}

En esta sección vamos a ver, a través de un caso práctico, cómo los aranceles permiten proteger a los productores nacionales y/o discriminar entre proveedores de distintos países que exportan sus avellanas a países de la U.E., entre ellos España. Para entender este caso hay que explicar que la producción de avellanas en España venía sufriendo una reducción

\footnotetext{
${ }^{3}$ Existe también la imposición a tanto alzado. En este caso se aplica un tipo de gravamen único a conjuntos de artículos cuya importación no tiene carácter comercial (como por ejemplo los equipajes).

${ }^{4}$ Véase la ficha técnica número 43 en Estrategia y gestión del comercio exterior, curso superior (2005).

${ }^{5}$ Este método es el que se aplica en el $95 \%$ de los casos.

${ }^{6}$ En particular, los costes del embalaje, los costes de los envases que formen un todo con la mercancía, las comisiones y gastos de corretaje fuera de la $\mathrm{UE}$, los gasto de transporte y seguro hasta el punto de entrada en el territorio aduanero comunitario y los bienes suministrados por el comprador de forma gratuita o a precios reducidos y utilizados en la producción y venta para la exportación de las mercancías importadas.

${ }^{7}$ En particular, los impuestos, tasas y gravámenes satisfechos por la mercancía importada en el territorio aduanero comunitario, los gastos que se produzcan tras la llegada al territorio aduanero comunitario (descarga, almacenamiento, etc.), los gastos relativos a trabajos de construcción, instalación, montaje, mantenimiento, etc. realizados después de la importación, los gastos de transporte y seguro en el territorio aduanero comunitario y los Intereses resultantes de un acuerdo financiero entre el exportador e importador relativo a la compra de las mercancías.

${ }^{8}$ Son mercancías comunitarias: las obtenidas totalmente en territorio aduanero; las importadas y despachadas a libre práctica; y, las obtenidas en el territorio aduanero a partir de las anteriores.

${ }^{9}$ El Sistema de Preferencias Generalizadas consiste en la aplicación de aranceles reducidos o nulos a determinados productos procedentes de los países en desarrollo.
} 
La empresa española PACKSEK S.A. se abastece de avellanas de proveedores extremeños así como de proveedores de otros países. Dicha empresa prepara bolsas de frutos secos con cáscara para la campaña navideña. Para la campaña de este año necesita importar $13.500 \mathrm{Kg}$. de avellanas.

Después de contactar con varios proveedores internacionales recibe 3 ofertas de similar calidad de productores de distinta procedencia (EE.UU., Chile y Turquía). Los productores de EE.UU. le presentan una oferta de 0,42 \$ USA por Kg. de avellanas. Los productores de Chile ofertan sus avellanas a 0,39 \$ USA por Kg. Finalmente, los productores de Turquía ofrecen sus avellanas a 0,41 \$ USA por Kg.

Para el cálculo de la oferta de cada país hay que tener en cuenta la siguiente información:

- Costes de transporte: $200 €$ desde EE.UU., $725 €$ desde Chile y $492 €$ desde Turquía.

- Tipo de cambio spot $1 €=1,25 \$(1 \$=0,80 €)$.

- Lugar de importación: Valencia Puerto.

- Los gastos de tramitación de la importación, de descarga y portuarios presupuestados se elevan a $210 €$.

- Tarifas arancelarias: el alumno debe conectarse a la dirección electrónica http:/www.taric.es (Acceso a servicios, Demo arancel netTaric y pinchar en la parte de abajo en [Entrar en la demo netTaric]) con el fin de obtener la información requerida. Una vez en esta página web el alumno deberá localizar el código arancelario del producto que se desea importar (a través del buscador de productos), así como los aranceles que se exigen para la importación de dicho producto, en función del origen de las importaciones.

- Otra información: también deberá obtener la información del tipo IVA aplicable a dicho producto así como la necesidad de algún certificado (sanitario u otros) para poder importar avellanas a la U.E.

Cuadro 1. Anuncio para la práctica de aranceles.

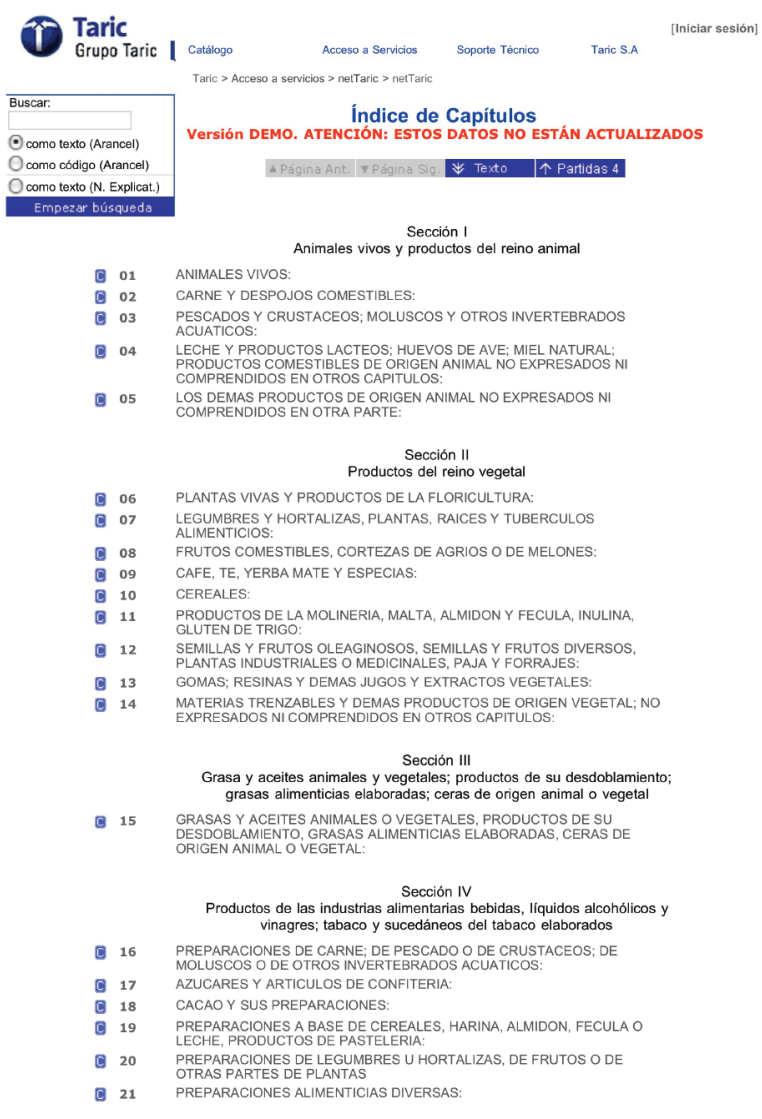

Figura 1- Índice web Taric.

progresiva desde finales de los años 70, debido especialmente a la irrupción en el mercado internacional de productores extranjeros que ofrecían avellanas a precios por debajo de precio ofrecido por los productores domésticos españoles. Ante esta situación y dado que la producción de avellanas es un sector tradicional en España y que además se trataba de una producción muy concentrada en determinadas áreas, se decidió proteger a los productores domésticos de la competencia extranjera a través de un arancel. La imposición del arancel automáticamente supuso el aumento del

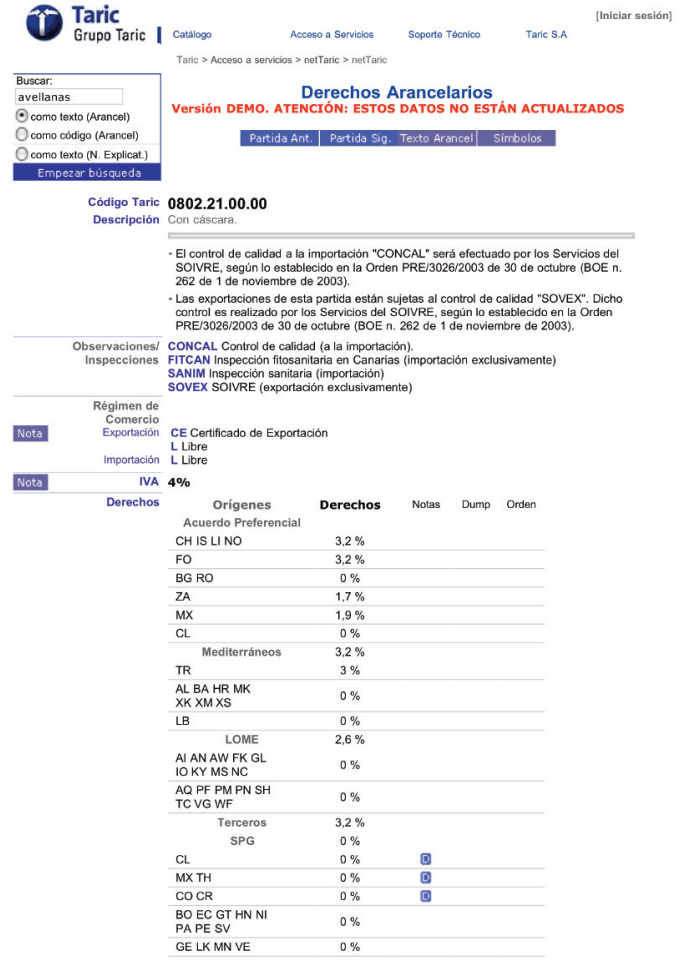

Figura 2- Web derechos arancelarios.

precio de la avellanas dentro de nuestras fronteras, con lo que los productores nacionales podían ofrecer sus avellanas a un precio superior. El aumento del precio interno tras la imposición del arancel incentiva al aumento de la producción interior. En este sentido el arancel es un instrumento de protección de la producción doméstica. Como veremos a continuación, alguno de los proveedores que inicialmente pueden ofrecer sus avellanas en nuestras fronteras a un precio más barato que los productores domésticos, tras el arancel sus precios se ven incrementados y dejan de ser tan competitivos.

Para ilustrar en la práctica el caso descrito, en esta sección se presenta el caso tal y como se les plantea a los alum- 
RESPUESTAS

1.¿Cuál es el código arancelario correspondiente a esta mercancía?

El código arancelario correspondiente a las avellanas con cáscara es el 0802.21.00.00

2.¿Cuáles son los derechos de importación que se tendrán que abonar según el país del proveedor?

El tipo arancelario si importamos la mercancía desde EE.UU. es del 3,2\%. Si decidimos importar avellanas desde Chile el tipo arancelario sería del o,o\%. Finalmente, si importamos avellanas desde Turquía el tipo arancelario sería del 3,2\%.

3.¿Serán necesarios algunos certificados para la importación?

La importación desde un país de la U.E. no requiere de ningún certificado de calidad o sanitario. Sin embargo, la importación desde un país tercero requiere del certificado CONCAL (control de calidad a la importación) y del certificado SANIM (certificado sanitario). Si además la importación fuera a Canarias habría que aportar también el certificado fitosanitario FITCAN.

4.Calcular el valor en aduana y el coste total de la importación para los tres proveedores. ¿Qué proveedor es más barato?

El valor en aduana es el valor en factura más los costes de transporte más los gastos de trámites y portuarios. Vamos a calcular el valor en aduana (la base imponible del arancel) para cada país y a continuación le aplicaremos el arancel correspondiente de cada país.

Para EE.UU.:

$13.500 \mathrm{Kg}$. x 0,42 \$ el Kg.= 5.670 $\$$ x $0.80\left(\mathrm{TC}_{\$ / €}\right)=4.536 €($ Valor en euros de la mercancía importada desde EE.UU.) $200 €=$ Gastos de transporte desde EE.UU.

$210 €=$ Gastos de tramitación de la importación, de descarga y portuarios

Valor en aduana de la oferta de EE.UU.: $4.946 €(=4.536+200+210)$

Los aranceles para la importación de avellanas de EE.UU. son 4.926 x 0,032 = 158,272 €

Valor de la oferta del proveedor de EE.UU. incluidos los aranceles: 5.084,272 € $(=4.296+158,272)$

Para Chile:

$13.500 \mathrm{Kg}$. x $0,39 \$=5.265 \$$ x $0.80\left(\mathrm{TC}_{\$ / €}\right)=4.212 €$ (Valor en euros de la mercancía importada desde Chile)

$725 €=$ Gastos de transporte desde Chile

$210 €=$ Gastos de tramitación de la importación, de descarga y portuarios

Valor en aduana de la oferta de Chile: $5.085 €(=4.212+663+210)$

Los aranceles para la importación de avellanas de Chile son 5.147 x 0,00 $=0 €$

Valor de la oferta del proveedor de Chile incluidos los aranceles: $5.147 €(=5.147+0)$

Para Turquía:

$13.500 \mathrm{Kg}$. x $0,41 \$=5.535 \$$ x $0.80\left(\mathrm{TC}_{\$ / €}\right)=4.428 €$ (Valor en euros de la mercancía importada desde Turquía) $492 €=$ Gastos de transporte desde Turquía

$210 €=$ Gastos de tramitación de la importación, de descarga y portuarios

Valor en aduana de la oferta de Turquía: $5.130 €(=4.428+492+210)$

Los aranceles para la importación de avellanas de Turquía son 5.130 x 0,032 =164,16€

Valor de la oferta del proveedor de Turquía incluidos los aranceles: 5.294,16 € $(=5.130+164,16)$

Por tanto, el proveedor más barato (teniendo en cuenta los aranceles y los costes de transporte) es el de EE.UU.

Si tenemos en cuenta el IVA (4\%) del producto importado, la importación asciende a: $5.084,272 € \times(1+0.04)=5.287,643 €$

5.¿̇Qué documentos será necesario aportar para realizar la importación, y que trámites será necesario realizar?

Para poder realizar la importación de avellanas desde EE.UU. se necesitan los siguientes documentos: el Documento Único Ad ministrativo (DUA) de importación, la factura comercial, el documento de transporte (Conocimiento de embarque o Bill of landing), el certificado CONCAL, el cerificado sanitario SANIM, el certificado de origen de EE.UU. y el documento DV-1 donde se declara el valor en aduana.

\section{Cuadro 2. Respuestas al caso práctico.}

nos. La secuencia de esta práctica es la siguiente. La semana antes de resolver en clase el caso práctico los alumnos reciben las instrucciones del caso (bien se reparte en clase el anuncio de la práctica y sus instrucciones o bien se cuelgan las instrucciones en el aula virtual ${ }^{10}$ ). Con las instrucciones del caso práctico los alumnos deben recoger la información necesaria para poder resolver la práctica en clase (de forma presencial). Por último, los alumnos reciben en la clase práctica las preguntas a las que deben contestar para resolver la práctica. Estas preguntas se resuelven en clase con la ayuda del profesor (en aquellos aspectos más complicados). Tras la realización de la práctica, se recogen las respuestas de los alumnos y se presenta y discute la solución al caso. A conti- nuación se describen cada uno de los pasos para resolver la práctica de forma más detallada.

\subsection{Anuncio del caso práctico}

En el anuncio del caso práctico se les plantea a los alumnos un caso realista de cómo una empresa importadora de un determinado producto (cuya procedencia puede ser un país tercero o un país de la U.E.) decide de qué país importar, en base a las tarifas arancelarias vigentes, entre distintos proveedores. En el anuncio se les propone a los alumnos una serie de posibles proveedores situados en distintos países (con distintos costes de transporte) que producen un producto similar u homogéneo. Además, le proporcionamos información de cómo

${ }^{10}$ El aula virtual es una plataforma informática diseñada para la gestión de la asignatura. A través de la misma los profesores ponen a disposición de los alumnos el material de la asignatura que se considere apropiado para cada tema. 
obtener las tarifas arancelarias vigentes ${ }^{11}$. Un posible ejemplo del anuncio de esta práctica aparece en el Cuadro 1.

3.2. Solución del caso práctico

La segunda parte de esta práctica consiste en su resolución durante la siguiente clase. Para poder resolver este caso práctico es necesario que cada alumno haya recabado la información sobre aranceles, el tipo de IVA aplicable, así como la necesidad de presentar certificados sanitarios o de otro tipo para la importación del producto propuesto en el caso práctico.

El acceso a la información de la página www.taric.es se ilustra en la página web de dicho enlace (Figura 1). Como se puede observar en la parte superior izquierda de esta página web, existe un buscador que les permite a los alumnos buscar directamente el producto en cuestión. Alternativamente, se puede ir buscando el producto en función de los distintos capítulos de productos. Por ejemplo, las avellanas estarían dentro del capítulo o8 (Frutos comestibles,...). Si profundizamos la búsqueda de nuestro producto hasta el final, llegamos a una página en la que se presenta toda la información necesaria para resolver la práctica. En concreto la página web a la que accederíamos sería la Figura 2.

En esta página tenemos acceso a diferentes tipos de información. Primero, tenemos el código Taric de la mercancía objeto de importación (0802.21.00.00). A continuación se presenta la descripción simple del tipo de mercancía (en nuestro caso avellanas con cáscara) y los certificados y/o inspecciones necesarias para importar el producto. La siguiente información hace referencia al régimen de comercio al que está sujeta la mercancía. También tenemos la información del tipo de IVA del producto en cuestión ${ }^{12}$. Finalmente, aparece la información referente a los distintos tipos arancelarios en función del origen de las mercancías (Terceros países, Mediterráneos, SPG, Acuerdo preferencial).

La segunda parte de la práctica consiste en resolver las cuestiones que se les proponen a los alumnos. En concreto las preguntas que deben contestar los alumnos y sus correspondientes respuestas aparecen en el Cuadro 2.

A modo de resumen de este ejercicio práctico, los alumnos han podido comprobar, tras la resolución de este caso práctico, que los aranceles encarecen los productos que provienen del exterior (por ejemplo, las avellanas importadas de EE.UU. o de Turquía ven incrementados sus precios en un 3,5\% tras el arancel). Además, las distintas tarifas arancelarias (en función del país origen de las avellanas) suponen un trato discriminatorio entre distintos proveedores tranjeros. Así, se observa que el arancel que se impone a ex avellanas que provienen de Chile es cero, mientras quelas arancel que se impone a las avellanas que provienen ded EE.UU. o Turquía tienen un arancel de 3,5\%.

\section{Conclusiones.}

En este artículo se ha analizado cómo se aplican los aranceles a la importación a la U.E. de productos de terceros países. Para poder calcular los aranceles ha sido necesario explicar conceptos básicos relacionados con el arancel como son el valor en aduana y el origen de las mercancías. Para ilustrar cómo se calculan los aranceles se ha presentado un caso práctico de importación de un determinado producto. Este caso práctico se plantea como una práctica para los alumnos de un curso de comercio exterior. Para poder resolver la práctica el alumno necesita recabar información sobre los aranceles y otros elementos necesarios. La resolución del ejercicio permite a los alumnos entender porqué los aranceles son un instrumento de protección de la producción nacional y cómo los aranceles distorsionan la competitividad de los países en el mercado internacional.

\section{Bibliografía}

Operativa y práctica del comercio exterior. Curso básico. 2005. ICEX.

Estrategia y gestión del comercio exterior. Curso superior. 2005. ICEX.

Resolución de 15 de septiembre de 2008, del Departamento de Aduanas e Impuestos Especiales de la Agencia Estatal de la Administración Tributaria, en la que se recoge las instrucciones para la formalización del Documento Único Administrativo (DUA). BOE número 231, 24-09- 2008.

http://www.boe.es/boe/dias/2008/o9/24/pdfs/A3 8697-38698.pdf.

\footnotetext{
${ }^{11}$ Existen varias posibilidades de acceso a la información de tarifas arancelarias (por ejemplo en la página de la Agencia Tributaria). Sin embargo, la página www.taric.es proporciona a través de su demo una de las formas más fáciles de acceder a la información sobre tarifas arancelarias, así como otra información relacionada, como puede ser el IVA, los certificados y/o inspecciones necesarias, el régimen de importación, etc.

12 El IVA es un impuesto indirecto que grava el consumo en la UE, por tanto los tipos impositivos del IVA para las mercancías que importamos del exterior coinciden con los tipos de IVA que se aplican a los mismos productos dentro de la UE.
} 